\title{
Effects of a high daily dose of soy isoflavones on DNA damage, apoptosis and estrogenic outcomes in healthy, postmenopausal women - a Phase I clinical trial
}

\author{
Elena A. Pop, MD ${ }^{1}$, Leslie M. Fischer, PhD, MPH, RD ${ }^{1}$, April D. Coan, MPH $^{2}$, Matt \\ Gitzinger ${ }^{1}$, Jun Nakamura, $\mathbf{P h D}^{3}$, and Steven H. Zeisel, MD, $\mathrm{PhD}^{1,4}$ \\ 1 Department of Nutrition, School of Public Health and School of Medicine, University of North Carolina at \\ Chapel Hill, North Carolina, 27599-7461 USA \\ 2 Department of Biostatistics, School of Public Health and School of Medicine, University of North Carolina \\ at Chapel Hill, North Carolina, 27599-7461 USA
}

3 Department of Environmental Sciences and Engineering, School of Public Health and School of Medicine, University of North Carolina at Chapel Hill, North Carolina, 27599-7461 USA

4 Nutrition Research Institute, University of North Carolina at Chapel Hill. North Carolina, 27599-7461 USA

\begin{abstract}
Objective-A Phase I double blinded clinical trial was conducted to evaluate the effects of a high oral dose of soy isoflavones administered daily for 84 days to healthy, postmenopausal women.

Principal outcome measures included DNA damage, apoptosis and changes indicative of estrogenic stimulation.
\end{abstract}

Design-After eligibility and equol-producer status were determined, stratified randomization was used to assign subjects to the isoflavone (active) or placebo group. Of the 30 subjects who completed the study, 18 were in the active group. DNA damage was assessed via COMET and apurinic/ apyrimidinic site assays in lymphocytes. Apoptosis was evaluated via TUNEL and activated Caspase-3 assays in lymphocytes. Estrogenic/antiestrogenic effects were assessed using a self-report questionnaire and by assaying for estrogen, follicle-stimulating hormone, luteinizing hormone, and sex hormone binding globulin in blood.

\begin{abstract}
Results-In treated postmenopausal women there was no indication that high doses of soy isoflavones caused DNA strand breakage, increased AP sites, or increased apoptosis in peripheral lymphocytes. There were no significant changes in mean values for estrogenic effects or other laboratory measurements. Very few adverse events occurred and the only drug-related adverse events were mild or grade 1 in severity.
\end{abstract}

Conclusions-Unconjugated soy isoflavones appear to be safe and well tolerated in healthy postmenopausal women at doses of $900 \mathrm{mg}$ per day.

\footnotetext{
Address reprint requests and correspondence to Steven Zeisel, Nutrition Research Institute, School of Public Health and School of Medicine, University of North Carolina at Chapel Hill, CB\# 7461, Chapel Hill, NC 27599-7461. E-mail: steven_zeisel@unc.edu.

Dr. Zeisel serves on advisory boards for Dupont, Solae and Hershey Foods. He received grant support from Mead Johnson and from the Egg Nutrition Center. Solae is a producer of soybean derivatives, and makes soy isoflavones. A subsidiary of Dupont supplied the tested isoflavone mixture to the National Cancer Institute who then provided it to us. There are no other potential conflicts with the work described. Dr. Fischer is a consultant with Hannaford Bros., Co., and there is no conflict with the work described.
} 


\section{Keywords}

soy isoflavones; estrogenic effects; genotoxicity; apoptosis

\section{INTRODUCTION}

Many women supplement their diets with soy isoflavones because case-control studies conducted in China [1], and in Asian-Americans [2,3], as well as a prospective cohort study from Japan [4] showed an inverse relationship between soy intake and breast cancer risk. The chemopreventive effects of soybeans and soy-containing foods may be related to their isoflavone content $[5,6,7,8,9]$. Daily intakes of $39-47 \mathrm{mg} / \mathrm{day}$ isoflavones have been reported in Japanese populations [10,11]. In the United States, dietary consumption of soy isoflavones in the general population is much less than this amount $(<5 \mathrm{mg} /$ day $)$ and diet supplements are being used to increase daily intake. These isoflavones exert multiple effects including estrogen receptor activation [12,13] as well as antiestrogenic actions [14], antioxidant activity [14], inhibition of growth factor receptor signaling via tyrosine kinases $[15,16,17,18]$, induction of apoptosis [19,20,21,22], induction of cell differentiation [23], and inhibition of angiogenesis [24].

Some investigators reported that soy isoflavones, particularly genistein, caused gene damage [25]. Genistein induced mammalian topoisomerase II dependent DNA cleavage in purified broken cell preparations [26] and at high doses induced the production of large numbers of micronuclei (a measure of chromosomal damage) in mouse splenocytes in culture [27]. However, our earlier study in men treated with high dose soy isoflavones did not confirm this [28]; there was no increase in double stranded breaks in DNA. There is also significant concern that soy isoflavones have estrogenic actions that might increase proliferation in estrogen receptor positive breast cancers [29]. Soy isoflavones bind to both estrogen receptors (ER) $\alpha$ and $\beta$ and are $1 / 1000$ as potent as estrogen in activating ER $\alpha$ and $1 / 3$ as potent as estrogen for $\mathrm{ER} \beta$ [30]. At this time, there is considerable controversy as to whether isoflavones are net estrogen agonists [13,29,31] or whether they act via antiestrogenic effects [32]. One possible explanation may have to do with variations among women in the capacity to form the isoflavone metabolite, equol [33,34]. Equol binds to both ER $\alpha$ and ER $\beta$ and remains in circulation longer than do genistein or daidzein $[33,34]$. The capacity to form equol depends on colonization of the intestine with certain bacteria, and occurs in approximately 20-35\% of the Western adult population and 50-55\% of the population living in Asian countries [33]. The objective of this study was to determine whether or not healthy postmenopausal women developed estrogenic effects, genotoxicity or increased apoptosis when treated orally with a high dose isoflavone mixture (70\% unconjugated isoflavones containing genistein, daidzein and glycitein) for 84 days. In addition, we determined whether women, who produced the daidzein metabolite, equol, differed in these outcome markers from women who did not.

\section{METHODS}

\section{Subjects}

Healthy, non-obese postmenopausal women were recruited from the Research Triangle area of North Carolina by advertisements placed in local newspapers, mass informational emails, and flyers placed in strategic locations such as grocery stores, and churches. Postmenopausal status was defined as having last spontaneous menstrual bleeding $>12$ months ago and follicle stimulating hormone $(\mathrm{FSH})>30 \mathrm{mIU} / \mathrm{mL}$ (later amended to $27 \mathrm{mIU} / \mathrm{mL}$ as the laboratory method used for the analysis changed). Non-obese was defined as a body mass index (BMI) $<35 \mathrm{~kg} / \mathrm{m}^{2}$. Women taking hormone/estrogen therapy or selective estrogen receptor modulators (SERMS) within three months of enrollment or at high risk of breast cancer (five- 
year risk of $1.9 \%$ or higher) as assessed by NCI's Breast Cancer Risk Assessment Tool (http://bcra.nci.nih.gov) were excluded. Use of oral antibiotics within the three months prior to enrollment, supplements containing isoflavones within one month prior to enrollment, current tobacco use, or routine alcohol ingestion $>2$ drinks/day were also reasons for exclusion. Before acceptance into this study, the volunteer's health was verified by medical history, physical examination by a licensed medical doctor, screening laboratory tests, chest $\mathrm{x}$-ray and electrocardiogram. In addition, the subject was required to furnish copies of negative mammogram and Pap smear reports dated within the last year.

Seventy-two women met eligibility criteria based on an initial telephone screen and were scheduled for a two-part screening appointment. Thirty-eight subjects met initial eligibility after screening and 36 women were enrolled. One subject was terminated from the study due to FSH levels that were too low. Another two subjects completed the study, but their information was dropped because it was later determined that their pre-study mammograms were not normal. Three other subjects decided not to complete the study. One subject moved to another state, one stated that the study supplement made her irritable and another claimed personal reasons for not completing the study. The remaining 30 subjects successfully completed the study. Demographic information on these subjects is presented in Table 1.

The subjects provided written, informed consent, and the study was conducted in accordance with the guidelines of the Institutional Review Board of the School of Medicine at the University of North Carolina (UNC) at Chapel Hill. We operated under an Investigational New Drug (IND) application (no. 54137) for the isoflavone preparation, which was obtained from the Food and Drug Administration by the National Cancer Institute (NCI) for use in cancer prevention trials. Westat (Rockville, Maryland), the monitoring agency designated by NCI, conducted a complete evaluation of study procedures and study event documentation.

\section{Equol status}

After eligibility was determined, all subjects ingested $473.2 \mathrm{~mL}$ of soy milk containing $50 \mathrm{mg}$ of daidzein [33] to determine if they were producers of the daidzein metabolite equol. After 18 hours, blood was collected and serum equol was determined by Dr. Kenneth Setchell at Cincinnati Children's Hospital Medical Center using high-pressure liquid chromatography mass spectrophotometry $[33,34]$. Equol producers were defined as individuals with plasma equol concentrations $>20 \mu \mathrm{g} / \mathrm{L}$; non-equol producers as those with equol concentrations < $10 \mu \mathrm{g} / \mathrm{L}$. Individuals with intermediate equol concentrations $(\geq 10 \mu \mathrm{g} / \mathrm{L}$ to $\leq 20 \mu \mathrm{g} / \mathrm{L}$ ) were to be excluded from the study; however, reanalysis of plasma samples revealed that one included subject was an intermediate producer.

\section{Isoflavones formulation and dosage}

Protein Technologies International (PTI; St. Louis, MO), via the National Cancer Institute, provided hard gelatin capsules that contained $\geq 70 \%$ active substance as total unconjugated isoflavones (PTI G-2535 Unconjugated Isoflavones-70). Isoflavones were produced under Good Manufacturing Practices guidelines. University Pharmaceuticals of Maryland Incorporated (Baltimore, MD) formulated each capsule to contain $150 \mathrm{mg}$ genistein activity. The composition of PTI G-2535 capsules (Lot \# UPM 9809-021) used in this clinical study was as follows: genistein $139.5 \mathrm{mg}$ per capsule, daidzein $74 \mathrm{mg}$ per capsule and glycitein 11 mg per capsule. Two laboratories (Ralston Analytical Laboratories, St. Louis, MO; Sigma Chemical Laboratories, St. Louis, MO) independently analyzed isoflavone composition and concentrations. The preparation was stable at $40^{\circ} \mathrm{C}$ and $70^{\circ} \mathrm{C}$ for at least 6 months, and at $25^{\circ}$ $\mathrm{C}$ for 3 years (assays performed at University Pharmaceuticals of Maryland, Inc.). The placebo capsules were identical in size and color, and contained excipients from the active formulation. 


\section{Study design}

The study was conducted at the UNC General Clinical Research Center (GCRC). On day 1 (pre-study drug), blood was drawn from the antecubital vein for pre-study determinations and stratified randomization (based on equol producer vs. non-producer status) was then used to assign the eligible subjects to Active or Placebo groups.

The Active group $(n=18)$ received 4 capsules of dietary supplement PTI G-2535 (containing approximately $600 \mathrm{mg}$ genistein/day - about ten times the dose conventionally used in diet supplements - and half this much daidzein) divided into two equal daily doses. The Placebo group $(n=12)$ received the same number of placebo capsules. Subjects self-administered the capsules with food both in the morning and in the evening for 84 days. In order to effectively monitor genistein concentrations, subjects were instructed not to consume diets containing > $20 \mathrm{mg}$ genistein/day while enrolled in the study. Most subjects chose to abstain from soy altogether during their study participation. Follow-up visits were conducted on days 2, 7, 14, $28,56,84$ and 112.

\section{Monitoring of compliance and safety}

Compliance was determined using capsule counts and total plasma genistein concentrations (blood sample drawn before the next dose in the morning on days 2, 7, 14, 28, 56 and 84). Plasma was analyzed for total genistein using high-pressure liquid chromatography as previously described [35] except that we used an electrochemical detector (ESA Inc, Chelmsford, MA). We used trough genistein concentrations to detect individuals who accumulated genistein on the treatment, and reduced the administered dose by $50 \%$ if the trough concentration exceeded $10,000 \mathrm{ng} / \mathrm{mL}$ (this level is based on the highest trough level (7300 $\mathrm{ng} / \mathrm{mL}$ ) seen in a previous study [28], with a $33 \%$ margin added). All subjects were followed until 112 days after initiation of the study; 28 days after cessation of treatment.

Treatment toxicity was monitored with a panel of blood tests collected on days 1, 14, 28, 84, and 112, consisting of a complete blood count (CBC), blood urea nitrogen (BUN)/creatinine ratio, alkaline phosphatase (AP), alanine aminotransferase (ALT), aspartate aminotransferase (AST), gamma-glutamyl transferase (GGT), amylase, lipase, and triglycerides. An additional toxicity panel consisting of electrolytes, calcium, magnesium, phosphorus, lactate dehydrogenase, albumin, uric acid, total bilirubin, fibrinogen, prothrombin time (PT), partial prothrombin time (PTT), thyroxine (T4), thyroid-stimulating hormone (TSH), triiodothyronine (T3) uptake, and free thyroxine index (FTI) was measured on days 1, 28, 84, and 112. Finally, blood pressure measurements were taken on days 1, 2, 7, 14, 28, 56, 84 and 112.

Per the regulations set forth by the UNC Institutional Review Board, all adverse events were classified by the study physician as mild, moderate, or serious, and were graded according to the National Cancer Institute's Common Toxicity Criteria. Moreover, the study physician deemed these events 1) not or unlikely related to the study, 2) unknown, or 3) probably or definitely related to the study using her best clinical judgment. Specifically, if the adverse event was anticipated based on our previous results, or in the published literature, and was temporally related to isoflavone treatment, then it was deemed as probably study related. If the relation of the event to isoflavone treatment was not conclusively related, but could not be ruled out, then the attribution of the event to the isoflavone treatment was deemed as unknown. Events which were clearly unrelated to isoflavone treatment (for example events of known etiologies, or events which temporally preceded the first isoflavone dose) were deemed as unlikely study related. All subjects in whom adverse events occurred were followed according to Good Clinical Practice guidelines until resolution of the events. 


\section{Assessment of estrogenic/antiestrogenic effects}

Estrogenic/antiestrogenic effects of isoflavones were measured using a self-report questionnaire covering menopausal side effects (including hot flashes, chest pain, shortness of breath, leg cramps or swelling, breast tenderness, breast enlargement, changes in sex drive, nausea or vomiting) and by measuring serum concentrations of estrogen, $\mathrm{FSH}$, luteinizing hormone (LH), and sex hormone binding globulin (SHBG) on days 1, 84, and 112. Attempts were made to obtain endometrial biopsy samples from all subjects pre- and post-dose, but we were unable to collect sufficient material to assess the estrogen-responsiveness of this tissue.

\section{Assessment of genotoxicity and apoptosis}

The potential of genistein to induce DNA damage was assessed via COMET assay in lymphocytes collected on days 1 and 84 . This result was complemented by apurinic/ apyrimidinic (AP) sites assay in lymphocytes on the same days. Changes in apoptosis were evaluated via terminal deoxynucleotidyl transferase-mediated dUTP nick end labeling (TUNEL) and Caspase-3 activation assays conducted on lymphocytes collected on days 1 and 84.

Peripheral lymphocytes were isolated from blood using Ficoll-Hypaque gradient in evacuated tubes with sodium citrate (Vacutainer CPT; Becton Dickinson, Franklin Lakes, NJ) according to manufacturer's instructions [36,37]. Single cell gel electrophoresis (COMET) was performed as described previously $[38,39,40]$; this assay detects changes in DNA migration caused by strand breaks, alkaline labile sites or transient repair sites. Lymphocytes were sandwiched between $0.5 \%$ regular agarose solution (Fisher, Fair Lawn, NJ) and $0.5 \%$ Low Melting Point Agarose $\left(37^{\circ} \mathrm{C}\right.$; Fisher). The resulting slides were placed into cold, freshly made lysis solution $(10 \mathrm{mmol} / \mathrm{L}$ Tris base, $\mathrm{pH} 10,2.5 \mathrm{~mol} / \mathrm{L} \mathrm{NaCl}, 100 \mathrm{mmol} / \mathrm{L}$ EDTA, $1 \%$ Sodium Sarcosinate, $10 \%$ DMSO, and 1\% Triton X-100). Slides were placed in the refrigerator for a minimum of $1 \mathrm{~h}$, and then pretreated for $20 \mathrm{~min}$ in electrophoresis buffer $(300 \mathrm{mmol} / \mathrm{L} \mathrm{NaOH}$, $1 \mathrm{mmol} / \mathrm{L}$ EDTA, pH 13) for $20 \mathrm{~min}$. Electrophoresis was performed at 25 volts and $300 \mathrm{~mA}$ for $20 \mathrm{~min}$. After electrophoresis, slides were incubated three times for $5 \mathrm{~min}$ in neutralization buffer $(0.4 \mathrm{~mol} / \mathrm{L}$ Tris- $\mathrm{HCl}, \mathrm{pH} 7.5)$, washed with methanol and stained with ethidium bromide ( $20 \mu \mathrm{g} / \mathrm{mL}$; Sigma-Aldrich). For visualization of DNA damage, observations were made at 400x magnification using an Olympus AX70 fluorescent microscope (Olympus Corporation, Lake Success, NY). Typically 100 cells were analyzed per sample time point using cell image analysis software (Scion Corporation, Frederick, MD), and the COMET tail moment was calculated using a program in the NIH Image Analysis Macro language (National Technology Information Service, Springfield, VA).

The number of AP sites in genomic DNA from lymphocytes was quantified using a slot-blot method in which an aldehyde reactive probe was reacted with the aldehydic group of ringopened AP sites, as previously published [41]. The formation of AP sites can lead to the induction of base substitution mutations or inhibition of DNA replication [42].

We measured DNA fragmentation in lymphocytes by TUNEL using ApopTag in Situ Apoptosis Detection Kit (Chemicon International, Tamecula, CA). Lymphocytes were fixed in $2 \%$ paraformaldehyde, and suspended on a silanized microscope slide by cytospin. Following fixation the slides were stained with diaminobenzidine-peroxidase, and the nuclei counterstained with $0.5 \%$ methyl green. The slides were mounted, and the percent of TUNEL positive cells counted by light microscopy. At least 200 total cells were counted for each data point and the amount was expressed in percentage. We also assessed apoptosis using the Signal Stain Cleaved Caspase-3 (Asp175) IHC Detection Kit (Cell Signaling Technology, Danvers, MA). Briefly, this method detects endogenous levels of the large fragment $(17 / 19 \mathrm{kDa})$ of activated caspase-3 resulting from cleavage adjacent to Asp175. Lymphocytes were fixed in 
$2 \%$ paraformaldehyde and suspended on a silanized microscope slide by cytospin. Slides were incubated with prediluted cleaved Caspase-3 (Asp175) antibody which is bound by biotinylated secondary antibody. Avidin DH and horseradish peroxidase were complexed by mixing defined amounts prior to use, and the mixture subsequently was used to bind the secondary antibody. The macromolecular complex was localized by incubation with NovaRed enzyme substrate and the positive cells counted by light microscopy (at least 200 cells for each data point).

\section{Statistical analysis}

To examine the effect of treatment group (active or placebo) and time on trough plasma genistein concentrations, a repeated measures regression model was fit and various correlation structures were examined to take into account the fact the measures over time on the same person will be correlated. An unstructured correlation ultimately proved best. Treatment group and time as well as a treatment group by time interaction term were included in the model.

Descriptive and inferential statistical analyses were performed in order to look for trends that would point to differences in estrogenic effects, clinical laboratory tests, blood pressure, genotoxicity and apoptosis. Non-stratified (Active versus Placebo) and stratified (active equolproducers versus active non-equol producers) data were studied. Descriptive statistics (n, mean, standard error) were calculated for the measurements collected at day 1 and day 84, for the control and treatment groups and for the treated equol producer and non-equol producer groups. A permutation test was used to detect any differences in the mean change from day 1 to day 84 in the continuous response variables between groups (treated versus placebo and treated producers versus treated non-producers) and for the compared mean between groups at day 1 and day 84. A Fisher's exact test was used to detect any differences in the proportion of subjects that experienced side effects between the two groups. All analyses requiring a permutation test were performed using StatXact 4 (1989-1999, CYTEL Software Corporation, Cambridge, MA). All analyses using a Fisher's exact test were performed using SAS package Version 9.1 (SAS, Cary, NC). Based on COMET assay data (means, standard deviations) observed in our last study of isoflavone supplementation in men with prostate cancer (28), the current study had $80 \%$ power to detect a mean difference of 0.43 in COMET tail moment between the supplemented and control groups. A two-sided significance level of 0.05 was used for all statistical tests.

\section{RESULTS}

Demographic information on the subjects enrolled in the study is presented in Table 1. The mean age of subjects in the active group was $56.8 \mathrm{y}$ and in the placebo group was $53.5 \mathrm{y}$. The mean Body Mass Index (BMI) of subjects in the active group was 26.2 and in the placebo group was 25.2. The demographic profile for all of the subjects collectively who completed the study was $86.7 \%$ Caucasian, $10.0 \%$ African-American, and 3.3\% (1 subject) Asian-American.

\section{Equol producers versus non-equol producers}

Among the 30 volunteers completing the study, there were six equol producers (20\%; range: 21.8 to $46.6 \mathrm{ng} / \mathrm{mL}$ ) and 23 non-producers ( $80 \%$; range: 0 to $8.5 \mathrm{ng} / \mathrm{mL}$; See Table 1). Of these, 4 were assigned to the Active group and 2 were assigned to the Placebo group. One subject was an intermediate producer $(12.9 \mathrm{ng} / \mathrm{mL})$ and was assigned to the active group. As the number of equol producers was so small, results for producers and non-producers were pooled. However a cautious comparison of results seen in producers relative to non-producers in the Active group is presented at the end of the results section. 


\section{Trough genistein levels}

Two subjects in the Active treatment group had trough genistein concentrations that measured above the $10,000 \mathrm{ng} / \mathrm{mL}$ cut-off and thus had their daily dose halved as a result. A third subject in the active treatment group had her daily dose halved on day 2 due to her low body weight and because her trough genistein concentration measured close to $10,000 \mathrm{ng} / \mathrm{mL}$ on day 2 . All subjects in the Active group $(\mathrm{n}=18)$ had measurable trough genistein concentrations at every follow-up study visit; the mean trough level during the treatment phase (through Day 84) being $3103 \mathrm{ng} / \mathrm{mL}$. The mean trough genistein concentration among the 12 subjects in the Placebo group was $11 \mathrm{ng} / \mathrm{mL}$. Genistein trough levels (means and standard errors) for each follow-up study visit are given in Table 2.

\section{Adverse Events and Safety Data}

A summary of all adverse events, judged to be probably or possibly related to soy isoflavone administration, is presented in Table 3. (Note: subjects were monitored during the entire study for safety reasons and data was collected for each study day, but the statistical analysis was made only for days 1 (baseline) and 84 (end of treatment) to determine the significant changes that may have occurred during the study).

Analysis of the laboratory clinical measurements showed no significant change in the mean difference at day 84 from day 1, when comparing Placebo and Active groups. One subject, on placebo, experienced a Grade 1 asymptomatic elevation in TSH $(4.74 \mu \mathrm{U} / \mathrm{ml}$, reference range $0.46-4.68 \mu \mathrm{U} / \mathrm{mL}$ ) on Day 28 that returned to normal by the next visit. This same subject had a decreased T4 $(5.3 \mu \mathrm{g} / \mathrm{dL}$; reference range $5.5-11.0 \mu \mathrm{g} / \mathrm{dL})$ measurement on Day 84. Further investigations made by her primary care physician showed normal thyroid indices. Isolated decreases in T4 (not graded) occurred in four other subjects, one on active treatment (5.0 $\mu \mathrm{g}$ / $\mathrm{dL}$; reference range $5.5-11.0 \mu \mathrm{g} / \mathrm{dL})$ and three on placebo $(5.1 \mu \mathrm{g} / \mathrm{dL}, 5.1 \mu \mathrm{g} / \mathrm{dL}$, and $5.2 \mu \mathrm{g} /$ $\mathrm{dL}$; reference range $5.5-11.0 \mu \mathrm{g} / \mathrm{dL}$ ). By the end of the study the T4 values were normal in all subjects. Other thyroid indices for these 4 subjects were within normal limits at all measurement points. At no time did any of the five subjects who experienced out-of-reference-range thyroid indices complain of any of the symptoms of hypothyroidism. Measurements made at all other study visits were within the normal range. One treated subject experienced one transient Grade 1 elevation of AST ( $44 \mathrm{U} / \mathrm{L}$; reference range 14-38 U/L) on study day 28 which was deemed possibly related to study drug. This same subject had one episode of elevated triglycerides (340 $\mathrm{mg} / \mathrm{dL}$; upper limit of normal $=300 \mathrm{mg} / \mathrm{dL}$ ) on study day 14 which met Grade 1 criteria and was judged possibly related to study drug. One subject in the Placebo group experienced one episode of Grade 1 elevation in amylase (132 U/L; reference range 30-110 U/L) on Day 14, which was deemed unlikely related to study drug.

Two subjects in the Active group experienced intermittent episodes of increased blood pressure $(148 / 70 \mathrm{mmHg} ; 158 / 98 \mathrm{mmHg})$ that were judged to be possibly related to taking study drug (Table 3). When statistical analysis was performed, no significant changes in mean systolic or diastolic blood pressure were noted (Table 4).

\section{Estrogenic/antiestrogenic effects}

There were no clinically significant changes in estrogenic/antiestrogenic laboratory measurements (estrogen, FSH, LH, SHBG) (Table 4) between the groups. One subject on placebo experienced decreased FSH (11.0 mIU/L; reference range $21.5-131 \mathrm{mIU} / \mathrm{L})$ and $\mathrm{LH}$ (6.2 $\mathrm{mIU} / \mathrm{L}$; reference range $13.1-86.5 \mathrm{mIU} / \mathrm{L})$ levels on day 84 . These levels were within the normal range when measured on day 112. Another subject on placebo had increased estrogen on day $1(25 \mathrm{pg} / \mathrm{ml}$; reference range $<20 \mathrm{pg} / \mathrm{mL})$, which returned to normal during the study and increased again on day $112(60 \mathrm{pg} / \mathrm{ml}$; reference range $<20 \mathrm{pg} / \mathrm{mL})$. Her estrogen value 
was normal when rechecked on day 133. All three lab abnormalities were considered adverse events that were possibly related to study drug (Table 3 ).

Information on estrogenic effects of soy isoflavones was also assayed by a self report instrument which asked about hot flashes, breast changes and other menopausal symptoms (Table 3). Throughout the course of the study eight of eighteen (44\%) subjects in the Active group reported estrogenic or anti-estrogenic effects, three-fourths of these being increases in severity or frequency of hot flashes. In the Placebo group over the whole course of the study, four of the twelve (33\%) subjects reported estrogenic or anti-estrogenic effects, three-fourths of these being increases in frequency of hot flashes. In order to assess effects on hot flashes after prolonged soy treatment, a statistical analysis of all subjects experiencing hot flashes between study days 56 and 84 was performed. During this period, fifty percent (6 of 12) of the subjects on placebo reported increased hot flashes frequency, while $17 \%$ (3 of 18) of the subjects on isoflavones did so (proportions not significantly different). One subject on placebo reported increased breast tenderness on day 84 .

\section{Genotoxicity and apoptosis}

The means for COMET, TUNEL and Caspase- 3 assays were similar for the active and placebo groups at baseline (day 1) and day 84 . The mean for AP-site number at day 84 was higher in the Placebo group $(\mathrm{p}<0.05)$, however, there were no significant differences between the Placebo and Active groups in mean change in AP site number from day 1 to day 84 (Table 4).

\section{Equol producer status -possible effects}

A secondary aim of this study was to determine whether women who are equol-producers have different responses to isoflavones than women who are not equol-producers. Twenty percent (six subjects) of the subjects enrolled in the study were equol producers. This percent is comparable to what has been reported in the literature (33). The number of producers may have been slightly smaller in our study due to the small sample size and random variation. Despite these small numbers, we statistically analyzed the producers versus non-producers from the Active group in order to generate hypotheses about the impact of equol production status on response to isoflavone administration. Analysis of the laboratory clinical measurements showed no statistically significant difference in mean values at day 1 and day 84. Means between the groups were comparable, except that neutrophil count at day 1 was significantly higher for treated non-producers. There were no differences between groups in COMET, TUNEL or AP-site assay. However, activated Caspase- 3 was higher in treated producers on day 1 and between days 1 and 84, equol-producers in the Active group decreased Caspase-3 activation, while non-producers increased activation, although none of these results were statistically significant. There was a significant difference between the non-producers and producers of equol in the Active group in the percentage of subjects who experienced hot flashes as reported on day 84. No subjects reported hot flashes in the non-producers group on isoflavones, while $50 \%$ reported hot flashes in the producer group.

\section{DISCUSSION}

In a previous study in men with prostate cancer, we reported little toxicity or estrogenicity after 84 days of treatment with high dose isoflavones [28]. However, as all of these men had taken or were on a stable course of hormone therapy as part of their cancer treatment, it was difficult to determine the relationship of any observed symptoms to isoflavone administration. In the same study, the potential genotoxicity of isoflavone administration also was examined. Overall, no changes in average COMET occurred over the course of the treatment. However in 3 individuals we observed increases in COMET, and in one of these individuals we observed an increased micronucleus frequency. As this previous study was conducted in subjects who had 
cancer and who were potentially exposed to genotoxic drugs and treatments, it was difficult to definitively determine the relationship of isoflavones to the observed genotoxic effects. For this reason, in the present study we administered high dose isoflavones to healthy individuals at a daily dose that greatly exceeded (by approximately 10-fold) doses likely to be selfadministered by those using dietary supplements.

As discussed earlier, several studies conducted in cell culture showed DNA damage and micronucleus formation after exposure to genistein $[25,26,43,44,45,46]$. In this study we found no evidence for genotoxicity in the lymphocytes of the healthy subjects exposed to high doses of isoflavones. This suggests that short term supplementation ( 84 days) with high doses of soy isoflavones is safe in postmenopausal women.

In previous studies it was shown that genistein induced apoptosis in cells by inhibiting tyrosine kinase growth signaling [22,47,48]. Also, topoisomerase II, an enzyme involved in the relaxation and uncoiling of DNA (decatenation), is inhibited by genistein [49]. This process involves double strand breaks followed by religation [49,50]. We observed no significant changes in apoptosis as assessed by TUNEL for any of the groups in our study. Caspase- 3 was not significantly different between placebo and treated groups. The fact that between days 1 and 84, equol-producers in the Active group decreased Caspase-3 activation, while nonproducers increased activation (not statistically significant) however suggests that equol itself may inhibit apoptosis, or, alternatively, that the diversion of daidzein to form equol may lower the concentration of an active constituent or metabolite derived from isoflavones that induces apoptosis.

There was a trend toward lower incidence of hot flashes after three months on the soy isoflavones but overall we cannot conclude that soy isoflavones will reduce symptoms associated with menopause if used in postmenopausal women as these self-reported symptoms are prone to reporter bias and placebo effects. The significant difference between the nonproducers and producers of equol in the Active group in the percentage of subjects who experienced hot flashes as reported on day 84 suggests that equol production status may increase the anti-estrogenic potential of soy isoflavones.

There were no clinically significant changes in hormone or hormone-related laboratory values that suggested estrogenic or antiestrogenic activity of isoflavones in postmenopausal women. This is an important observation, as concerns about potential estrogenic activity of isoflavones has limited their use as a dietary supplement in women for fear that latent breast cancer cells might be stimulated to grow [51]. However, the lack of changes in hormone levels can only be taken as correlative and not as absolute evidence that soy isoflavones did not exhibit estrogenic activity in this sample of postmenopausal women. Unfortunately, the estrogenic potential of the soy isoflavones was not directly assessed in an estrogen-dependent tissue such as vagina or uterus. Attempts were made to collect endometrial biopsy samples, but insufficient tissue was available to look at pathological or biochemical changes. Thus any assessment of soy isoflavone estrogenicity must be interpreted with caution.

It is well known that menopause is associated with a dramatic rise in prevalence of hypertension in women and previous clinical and animal investigations have suggested that estrogen has a protective role against hypertension. However some clinical trials have found contradictory results [52]. Conflicting evidence on the effects of soy isoflavones on blood pressure also has been reported [53]; thus, we asked if a very high dose of isoflavones would make a difference and establish a directional effect of soy on blood pressure. The results of our analysis suggest that 84 days of treatment with soy isoflavones did not result in appreciable changes in blood pressure. 


\section{CONCLUSIONS}

In summary, these results suggest that unconjugated soy isoflavones are safe and well tolerated in healthy postmenopausal women at doses of $900 \mathrm{mg}$ per day. Very few adverse events occurred and the only drug-related adverse events were mild in severity. Although there has been considerable debate on the estrogenic potential of isoflavones, our study showed only very minimal effects. However, as narrow inclusion-exclusion criteria were chosen due to potential safety reasons related to treating post-menopausal women with very high doses of soy isoflavones these results may not hold for all post-menopausal women. Equol could be an important modulator of soy isoflavones and larger studies on the effects of isoflavone supplementation in humans are warranted.

\section{Acknowledgements}

This work was funded by the NCI (NCI-N01-CN-75035). Support for this work was also provided by grants from the NIH to the UNC Clinical Nutrition Research Unit (DK56350), the UNC General Clinical Research Center (RR00046) and the Center for Environmental Health and Susceptibility (ES10126).

We thank the staff of the UNC general Clinical Research Center for their help with the conduct of this study. We are also grateful to Joseph Galanko for assistance with statistical analyses.

\section{References}

1. Dai Q, Shu XO, Jin F, Potter JD, Kushi LH, et al. Population-based case-control study of soyfood intake and breast cancer risk in Shanghai. Br J Cancer 2001;85:372-378. [PubMed: 11487268]

2. Wu AH, Wan P, Hankin J, Tseng CC, Yu MC, et al. Adolescent and adult soy intake and risk of breast cancer in Asian-Americans. Carcinogenesis 2002;23:1491-1496. [PubMed: 12189192]

3. Wu AH, Yu MC, Tseng CC, Twaddle NC, Doerge DR. Plasma isoflavone levels versus self-reported soy isoflavone levels in Asian-American women in Los Angeles County. Carcinogenesis 2004;25:7781. [PubMed: 14555615]

4. Yamamoto S, Sobue T, Kobayashi M, Sasaki S, Tsugane S. Soy, isoflavones, and breast cancer risk in Japan. J Natl Cancer Inst 2003;95:906-913. [PubMed: 12813174]

5. Messina MJ, Persky V, Setchell KD, Barnes S. Soy intake and cancer risk: a review of the in vitro and in vivo data. Nutr Cancer 1994;21:113-131. [PubMed: 8058523]

6. Messina M, Barnes S. The role of soy products in reducing risk of cancer. J Natl Cancer Inst 1991;83:541-546. [PubMed: 1672382]

7. Hebert JR, Hurley TG, Olendzki BC, Teas J, Ma Y, et al. Nutritional and socioeconomic factors in relation to prostate cancer mortality: a cross-national study. J Natl Cancer Inst 1998;90:1637-1647. [PubMed: 9811313]

8. Adlercreutz H, Mazur W. Phyto-oestrogens and Western diseases. Ann Med 1997;29:95-120. [PubMed: 9187225]

9. Messina M, Barnes S, Setchell KD. Phyto-oestrogens and breast cancer. Lancet 1997;350:971-972. [PubMed: 9329507]

10. Chen Z, Zheng W, Custer LJ, Dai Q, Shu XO, et al. Usual dietary consumption of soy foods and its correlation with the excretion rate of isoflavonoids in overnight urine samples among Chinese women in Shanghai. Nutr Cancer 1999;33:82-87. [PubMed: 10227048]

11. Arai Y, Uehara M, Sato Y, Kimira M, Eboshida A, et al. Comparison of isoflavones among dietary intake, plasma concentration and urinary excretion for accurate estimation of phytoestrogen intake. J Epidemiol 2000;10:127-135. [PubMed: 10778038]

12. Willard ST, Frawley LS. Phytoestrogens have agonistic and combinatorial effects on estrogenresponsive gene expression in MCF-7 human breast cancer cells. Endocrine 1998;8:117-121. [PubMed: 9704568]

13. Hargreaves DF, Potten CS, Harding C, Shaw LE, Morton MS, et al. Two-week dietary soy supplementation has an estrogenic effect on normal premenopausal breast. J Clin Endocrinol Metab 1999;84:4017-4024. [PubMed: 10566643] 
14. Gescher A, Pastorino U, Plummer SM, Manson MM. Suppression of tumour development by substances derived from the diet-- mechanisms and clinical implications. Br J Clin Pharmacol 1998;45:1-12. [PubMed: 9489587]

15. Fioravanti L, Cappelletti V, Miodini P, Ronchi E, Brivio M, et al. Genistein in the control of breast cancer cell growth: insights into the mechanism of action in vitro. Cancer Lett 1998;130:143-152. [PubMed: 9751267]

16. Uckun FM, Narla RK, Zeren T, Yanishevski Y, Myers DE, et al. In vivo toxicity, pharmacokinetics, and anticancer activity of Genistein linked to recombinant human epidermal growth factor. Clin Cancer Res 1998;4:1125-1134. [PubMed: 9607569]

17. Balabhadrapathruni S, Thomas TJ, Yurkow EJ, Amenta PS, Thomas T. Effects of genistein and structurally related phytoestrogens on cell cycle kinetics and apoptosis in MDA-MB-468 human breast cancer cells. Oncol Rep 2000;7:3-12. [PubMed: 10601582]

18. Akiyama T, Ishida J, Nakagawa S, Ogawara H, Watanabe S, et al. Genistein, a specific inhibitor of tyrosine-specific protein kinases. J Biol Chem 1987;262:5592-5595. [PubMed: 3106339]

19. Yoon HS, Moon SC, Kim ND, Park BS, Jeong MH, et al. Genistein induces apoptosis of RPE-J cells by opening mitochondrial PTP. Biochem Biophys Res Commun 2000;276:151-156. [PubMed: 11006098]

20. Kumi-Diaka J, Butler A. Caspase-3 protease activation during the process of genistein-induced apoptosis in TM4 testicular cells. Biol Cell 2000;92:115-124. [PubMed: 10879632]

21. Shao ZM, Alpaugh ML, Fontana JA, Barsky SH. Genistein inhibits proliferation similarly in estrogen receptor- positive and negative human breast carcinoma cell lines characterized by P21WAF1/CIP1 induction, G2/M arrest, and apoptosis. J Cell Biochem 1998;69:44-54. [PubMed: 9513045]

22. Li Y, Upadhyay S, Bhuiyan M, Sarkar FH. Induction of apoptosis in breast cancer cells MDA-MB-231 by genistein. Oncogene 1999;18:3166-3172. [PubMed: 10340389]

23. Constantinou AI, Krygier AE, Mehta RR. Genistein induces maturation of cultured human breast cancer cells and prevents tumor growth in nude mice. Am J Clin Nutr 1998;68:1426S-1430S. [PubMed: 9848511]

24. Fotsis T, Pepper M, Adlercreutz H, Fleischmann G, Hase T, et al. Genistein, a dietary-derived inhibitor of in vitro angiogenesis. Proc Natl Acad Sci U S A 1993;90:2690-2694. [PubMed: 7681986]

25. Boos G, Stopper H. Genotoxicity of several clinically used topoisomerase II inhibitors. Toxicol Lett 2000;116:7-16. [PubMed: 10906417]

26. Yamashita Y, Kawada S, Nakano H. Induction of mammalian topoisomerase II dependent DNA cleavage by nonintercalative flavonoids, genistein and orobol. Biochem Pharmacol 1990;39:737744. [PubMed: 2154993]

27. Record IR, Jannes M, Dreosti IE, King RA. Induction of micronucleus formation in mouse splenocytes by the soy isoflavone genistein in vitro but not in vivo. Food Chem Toxicol 1995;33:919-922. [PubMed: 7590538]

28. Miltyk W, Craciunescu CN, Fischer L, Jeffcoat RA, Koch MA, et al. Lack of significant genotoxicity of purified soy isoflavones (genistein, daidzein, and glycitein) in 20 patients with prostate cancer. Am J Clin Nutr 2003;77:875-882. [PubMed: 12663286]

29. Allred CD, Ju YH, Allred KF, Chang J, Helferich WG. Dietary genistin stimulates growth of estrogendependent breast cancer tumors similar to that observed with genistein. Carcinogenesis 2001;22:1667-1673. [PubMed: 11577007]

30. Sirtori CR. Risks and benefits of soy phytoestrogens in cardiovascular diseases, cancer, climacteric symptoms and osteoporosis. Drug Saf 2001;24:665-682. [PubMed: 11522120]

31. Hsieh CY, Santell RC, Haslam SZ, Helferich WG. Estrogenic effects of genistein on the growth of estrogen receptor-positive human breast cancer (MCF-7) cells in vitro and in vivo. Cancer Res 1998;58:3833-3838. [PubMed: 9731492]

32. Shao ZM, Shen ZZ, Fontana JA, Barsky SH. Genistein's "ER-dependent and independent" actions are mediated trough ER pathways in ER-positive breast carcinoma cell lines. Anticancer Res 2000;20 (4):2409-16. [PubMed: 10953303]

33. Setchell KD, Cole SJ. Method of defining equol-producer status and its frequency among vegetarians. J Nutr 2006;136:2188-2193. [PubMed: 16857839] 
34. Setchell KD, Clerici C, Lephart ED, Cole SJ, Heenan C, et al. S-equol, a potent ligand for estrogen receptor beta, is the exclusive enantiomeric form of the soy isoflavone metabolite produced by human intestinal bacterial flora. Am J Clin Nutr 2005;81:1072-1079. [PubMed: 15883431]

35. Thomas BF, Zeisel SH, Busby MG, Hill JM, Mitchell RA, et al. Quantitative analysis of the principle soy isoflavones genistein, daidzein and glycitein, and their primary conjugated metabolites in human plasma and urine using reversed-phase high-performance liquid chromatography with ultraviolet detection. J Chromatogr B Biomed Sci Appl 2001;760:191-205. [PubMed: 11530977]

36. Fotino M, Merson E, Allen F. Micromethod for rapid separation of lymphocytes from peripheral blood. Ann Clin Lab Sci 1971;1:131-133. [PubMed: 5154596]

37. Ting A, Morris P. A technique for lymphocyte preparation from stored heparinized blood. Vox Sang 1971:561-563. [PubMed: 5098546]

38. Singh NP, McCoy MT, Tice RR, Schneider EL. A simple technique for quantitation of low levels of DNA damage in individual cells. Exp Cell Res 1988;175:184-191. [PubMed: 3345800]

39. Collins AR, Ma AG, Duthie SJ. The kinetics of repair of oxidative DNA damage (strand breaks and oxidised pyrimidines) in human cells. Mutat Res 1995;336:69-77. [PubMed: 7528897]

40. Sauvaigo S, Serres C, Signorini N, Emonet N, Richard MJ, et al. Use of the single-cell gel electrophoresis assay for the immunofluorescent detection of specific DNA damage. Anal Biochem 1998;259:1-7. [PubMed: 9606136]

41. Nakamura J, Walker VE, Upton PB, Chiang SY, Kow YW, et al. Highly sensitive apurinic/ apyrimidinic site assay can detect spontaneous and chemically induced depurination under physiological conditions. Cancer Res 1998;58:222-225. [PubMed: 9443396]

42. Loeb LA, Preston BD, Snow ET, Schaaper RM. Apurinic sites as common intermediates in mutagenesis. Basic Life Sci 1986;38:341-347. [PubMed: 3741336]

43. Kulling SE, Metzler M. Induction of micronuclei, DNA strand breaks and HPRT mutations in cultured Chinese hamster V79 cells by the phytoestrogen coumoestrol. Food Chem Toxicol 1997;35:605613. [PubMed: 9225019]

44. Kulling SE, Rosenberg B, Jacobs E, Metzler M. The phytoestrogens coumoestrol and genistein induce structural chromosomal aberrations in cultured human peripheral blood lymphocytes. Arch Toxicol 1999;73:50-54. [PubMed: 10207614]

45. Strick R, Strissel PL, Borgers S, Smith SL, Rowley JD. Dietary bioflavonoids induce cleavage in the MLL gene and may contribute to infant leukemia. Proc Natl Acad Sci U S A 2000;97:4790-4795. [PubMed: 10758153]

46. Ross JA. Dietary flavonoids and the MLL gene: A pathway to infant leukemia? Proc Natl Acad Sci U S A 2000;97:4411-4413. [PubMed: 10781030]

47. Morris SM, Chen JJ, Domon OE, McGarrity LJ, Bishop ME, et al. p53, mutations, and apoptosis in genistein-exposed human lymphoblastoid cells. Mutat Res 1998;405:41-56. [PubMed: 9729267]

48. Salti GI, Grewal S, Mehta RR, Das Gupta TK, Boddie AW, et al. Genistein induces apoptosis and topoisomerase II-mediated DNA breakage in colon cancer cells. Eur J Cancer 2000;36:796-802. [PubMed: 10762754]

49. Michael McClain R, Wolz E, Davidovich A, Bausch J. Genetic toxicity studies with genistein. Food Chem Toxicol 2006;44:42-55. [PubMed: 16198038]

50. Markovits J, Linassier C, Fosse P, Couprie J, Pierre J, et al. Inhibitory effects of the tyrosine kinase inhibitor genistein on mammalian DNA topoisomerase II. Cancer Res 1989;49:5111-5117.

[PubMed: 2548712]

51. Messina M, McCaskill-Stevens W, Lampe JW. Addressing the soy and breast cancer relationship: review, commentary, and workshop proceedings. J Natl Cancer Inst 2006;98:1275-1284. [PubMed: 16985246]

52. Ashraf MS, Vongpatanasin W. Estrogen and hypertension. Curr Hypertens Rep 2006;8:368-376. [PubMed: 16965722]

53. Sacks FM, Lichtenstein A, Van Horn L, Harris W, Kris-Etherton P, et al. Soy protein, isoflavones, and cardiovascular health: an American Heart Association Science Advisory for professionals from the Nutrition Committee. Circulation 2006;113:1034-1044. [PubMed: 16418439] 
TABLE 1

Subject demographics and equol production status

\begin{tabular}{|c|c|c|c|c|}
\hline Group & Mean Age (years) & Mean BMI $\left(\mathrm{kg} / \mathrm{m}^{2}\right)$ & Race & Equol status \\
\hline Active (n=18) & $56.78 \pm 1.25$ & $26.15 \pm 0.89$ & $\begin{array}{l}\text { Caucasian }(\mathrm{n}=16) \\
\text { African-American } \\
\qquad(\mathrm{n}=2)\end{array}$ & $\begin{array}{l}\text { Producers }(n=4) \\
\text { Intermediate producer } \\
\quad(n=1) \\
\text { Non-producers }(n=13)\end{array}$ \\
\hline Placebo $(n=12)$ & $53.50 \pm 1.06$ & $25.23 \pm 1.02$ & $\begin{array}{c}\text { Caucasian }(\mathrm{n}=10) \\
\text { African-American } \\
(\mathrm{n}=1) \\
\text { Asian-American }(\mathrm{n}=1)\end{array}$ & $\begin{array}{c}\text { Producers }(n=2) \\
\text { Non-producers }(n=10)\end{array}$ \\
\hline
\end{tabular}

BMI= body mass index. Race was determined by subject report. Equol producer status was determined using a soy milk (containing 50 mg of daidzein) feeding challenge. After 18 hours, blood was collected and serum equol was determined. Equol producers were defined as individuals with plasma equol concentrations $>20 \mu \mathrm{g} / \mathrm{L}$; non-equol producers as those with equol concentrations $<10 \mu \mathrm{g} / \mathrm{L}$. Individuals with equol concentrations $\geq 10 \mu \mathrm{g} / \mathrm{L}$ to $\leq 20 \mu \mathrm{g} /$ $\mathrm{L}$ were defined as intermediate producers. 


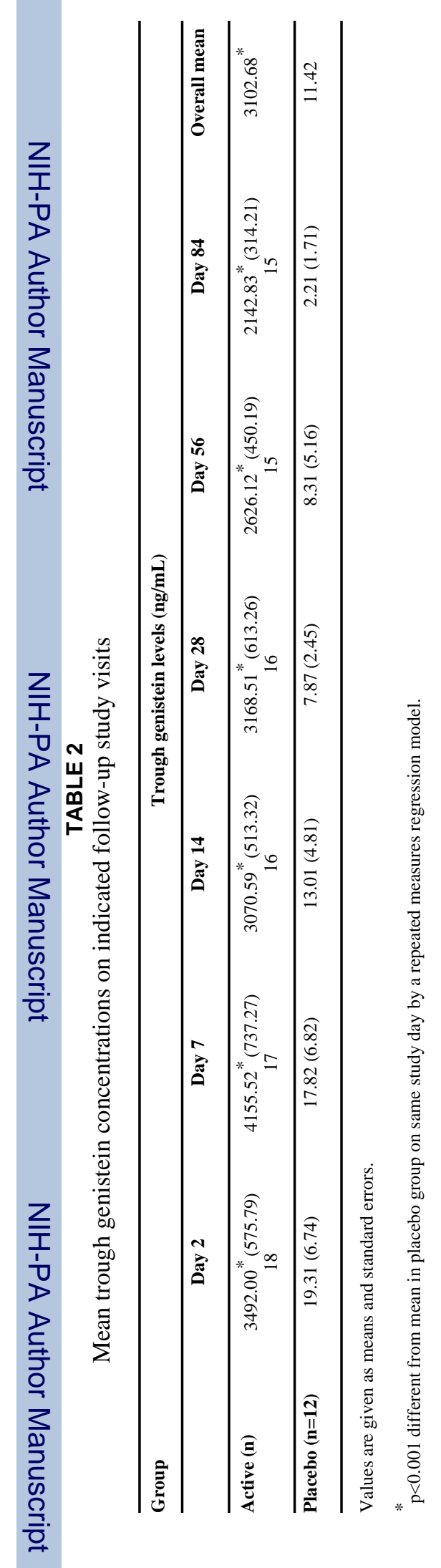


Table 3

Adverse events reported during isoflavone administration

\begin{tabular}{lll}
\hline Event Type & Number in Active Subjects & Number in Placebo Subjects \\
\hline Grade 1 adverse events possibly related to isoflavones & 2 \\
Increased blood pressure & 1 \\
Increased AST & 1 \\
Increased triglycerides & 0 \\
Increased estrogen & 0 \\
Decreased FSH/LH & 0 \\
Increased TSH & 1 \\
Decreased T4 & 0 \\
Flatulence & 1 \\
\hline Grade 1 adverse events probably related to isoflavones & 1 \\
Nausea & 1 \\
Swelling in legs (mild) & 0 \\
Breast tenderness & 0 \\
\hline Self-reported estrogenic/anti-estrogenic effects possibly related to isoflavones & \\
Hot flashes (Increased intensity or frequency) & 6 \\
Hot flashes (Decreased intensity) & 1 \\
Increased breast size or tenderness & 2 \\
\hline
\end{tabular}

Subjects were asked to report any side effects noticed during their study participation.

Abbreviations: AST- aspartate aminotransferase, FSH-follicle stimulating hormone, LH-luteinizing hormone, TSH - thyroid-stimulating hormone, T4tyroxine. 


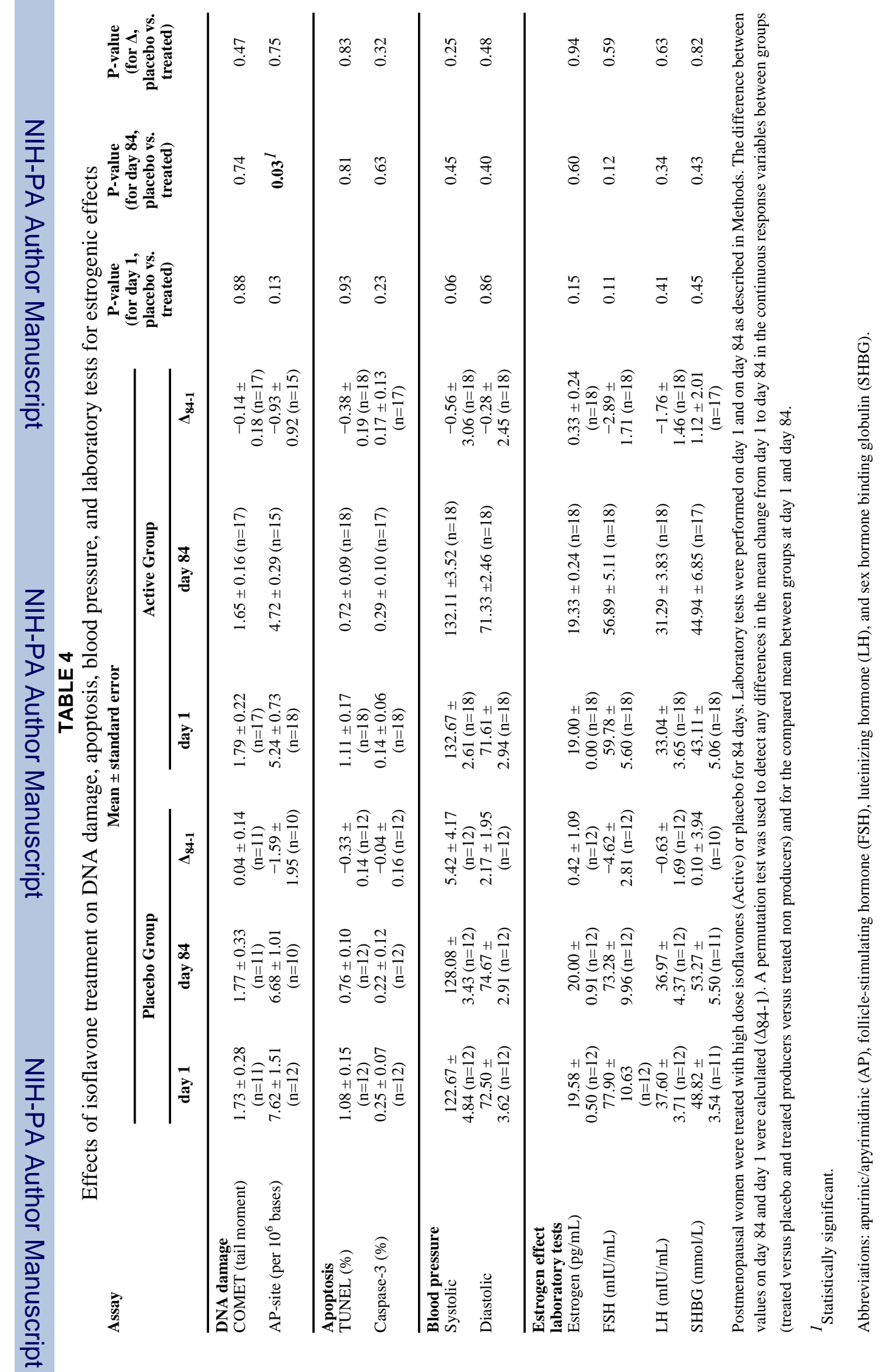

